\title{
Comparison of HPMC Inhalation-Grade Capsules and Their Effect on Aerosol Performance Using Budesonide and Rifampicin DPI Formulations
}

\author{
Li Ding, ${ }^{1}$ Ashlee D. Brunaugh, ${ }^{1}$ Rishi Thakkar, ${ }^{1}$ Christian Lee, ${ }^{1}$ Qingyan Jenny Zhao, ${ }^{1}$ Justin Kalafat, ${ }^{2}$ \\ Mohammed Maniruzzaman, ${ }^{1}$ and Hugh D. C. Smyth ${ }^{1,3}$
}

Received 29 July 2021; accepted 3 November 2021; published online 11 January 2022

\begin{abstract}
Despite the fact that capsules play an important role in many dry powder inhalation (DPI) systems, few studies have been conducted to investigate the capsules' interactions with respirable powders. The effect of four commercially available hydroxypropyl methylcellulose (HPMC)inhalation-grade capsule types on the aerosol performance of two model DPI formulations (lactose carrier and a carrier-free formulation) at two different pressure drops was investigated in this study. There were no statistically significant differences in performance between capsules by using the carrier-based formulation. However, there were some differences between the capsules used for the carrier-free rifampicin formulation. At 2-kPa pressure drop conditions, Embocaps ${ }^{\circledR}$ VG capsules had a higher mean emitted fraction (EF) $(89.86 \%)$ and a lower mean mass median aerodynamic diameter (MMAD) $(4.19 \mu \mathrm{m})$ than Vcaps ${ }^{\circledR}$ (Capsugel) $(85.54 \%, 5.10 \mu \mathrm{m})$ and Quali-V® I (Qualicaps) $(85.01 \%, 5.09 \mu \mathrm{m})$, but no significant performance differences between Embocaps ${ }^{\circledR}$ and ACGcaps ${ }^{\text {TM }}$ HI. Moreover, Embocaps ${ }^{\circledR} \mathrm{VG}$ capsules exhibited a higher mean respirable fraction $(\mathrm{RF}) /$ fine particle fraction $(\mathrm{FPF})$ with a $3-\mu \mathrm{m}$-sized cutoff $(\mathrm{RF} / \mathrm{FPF}<$ $3 \mu \mathrm{m})(33.05 \% / 35.36 \%)$ against Quali-V® I $(28.16 \% / 31.75 \%)(P<0.05)$, and a higher RF/ FPF with a 5 - $\mu \mathrm{m}$-sized cutoff $\left(\mathrm{RF} / \mathrm{FPF}_{<} 5 \mu \mathrm{m}\right)(49.15 \% / 52.57 \%)$ versus ACGcaps ${ }^{\mathrm{TM}} \mathrm{HI}$ $(38.88 \% / 41.99 \%)(P<0.01)$ at $4-\mathrm{kPa}$ pressure drop condition. Aerosol performance variability, pierced-flap detachment, as well as capsule hardness and stiffness, may all influence capsule type selection in a carrier-based formulation. The capsule type influenced $\mathrm{EF}, \mathrm{RF}, \mathrm{FPF}$, and MMAD in the carrier-free formulation.
\end{abstract}

KEY WORDS:: Pulmonary drug delivery; Inhalation capsule; Hydroxypropyl methylcellulose; Dry powder inhalers; Aerosol performance.

\section{INTRODUCTION}

Increasingly, pharmaceutical scientists are focused on the relationship between three important aspects of pulmonary drug delivery - the device, the drug/formulation powder, and the patient - and how these interactions affect the success of inhaled therapies. Predictability of the supplied dose is critical for product development in terms of quality and performance (1). Regulators and industry are also focusing on this when developing generic inhaler systems that must demonstrate bioequivalence (2). Failures in the development of novel or generic inhaled medicines might result from a lack of understanding regarding features of the drug/formulation

\footnotetext{
${ }^{1}$ Division of Molecular Pharmaceutics and Drug Delivery, College of Pharmacy, The University of Texas at Austin, Austin, TX 78712, USA.

${ }^{2}$ ACG North America, LLC. 262 Old New Brunswick Road, Suite A, Piscataway, NJ 08854, USA.

${ }^{3}$ To whom correspondence should be addressed. (e-mail: hugh.smyth@austin.utexas.edu)
}

powder $(3,4)$, device $(5-7)$, and/or the mechanisms by which they interact, in addition to pharmacologic causes.

Dry powder inhalers (DPIs) are commonly used to administer micronized drugs in a variety of formulations for the treatment of a variety of lung illnesses including lung infections such as cystic fibrosis (CF), pneumonia, tuberculosis (8), the severe acute respiratory syndrome-associated coronavirus 2 (SARS-CoV-2) (9), chronic obstructive pulmonary disorder (COPD)(10), and asthma (11). Metered-dose capsule or blister-based DPI devices, as well as multi-dose reservoir-based devices, are examples of DPI device technology (12). Capsule-based DPIs (cDPIs) are still the gold standard for inhaled drug/formulation powder therapeutic delivery (13). Multiple patient feedback systems (e.g., visual, auditory, and taste) have been found to ensure that the dose was provided accurately and consistently with cDPIs $(14,15)$. Hard-shell capsules are commonly used by cDPIs to deliver drug/formulation to the lungs. The cap and the body are two open-ended cylinders that make up the hard-shell capsule. The cap snaps on top of the body to complete the hard-shell 
capsule (16). Based on the film former, these hard-shell capsules utilized for dry powder inhalers can be further classified as gelatin, gelatin-polyethylene glycol (PEG), or hydroxypropyl methylcellulose (HPMC) capsules.

While several studies have been conducted to evaluate the device's interaction with the powder formulation $(5,6)$, very few studies have been conducted to investigate the capsule's influence and role on DPI performance. Existing studies have looked at drug retention in hard gelatin inhalation capsules (17), consequences of incorrect storage of inhalation capsules (18), drug deposition in the capsules with different lubricant levels (19), puncture test and emitted dose uniformity testing of a single capsule brand (20), and control of internal lubricant (21). Recently, some reports evaluating the aerodynamic performance of a formoterolbased dry powder formulation using 2 types of capsules (hypromellose and gelatin) from 2 manufacturers (Qualicaps ${ }^{\circledR}$ and Capsugel $\left.{ }^{\circledR}\right)$ under various storage conditions have also been reported $(22,23)$. However, only carrierbased formulation was studied.

Despite the few studies investigating inhalation capsules, they are a critical component in cDPIs. The capsule serves several important functions, and the properties of the capsule may significantly affect the performance of the entire product (24). The capsule is in direct contact with the powder formulation and thus interactions between the powder and the capsule surfaces are important to understand. During use, the capsule interface with the patient is also important (25). Also, the capsule must be pierced by the inhaler device, and these formed orifices are important to the exit of the powder from the capsule. During inhalation, the dynamics of the capsule motion in the device and the emission of the powder through the orifices may be primarily responsible for the redispersion of the powder into a respirable aerosol (26).

Thus, it is of interest to conduct investigations of inhalation capsules if one seeks to develop inhalation products with optimized performance and reduced variability. In this study, a comparison of performance between capsule brands is outlined. Specifically, we evaluated HPMC inhalation capsules from four different suppliers using aerosol performance analysis through cascade impaction testing using two different dry powder inhaler powder types as model formulations. Different from the previous studies given by Wauthoz et al.(22, 23), our findings in this study led to the aerosol performance variability, the pierced-flap detachment, and the hardness and stiffness capsule and formulation type importance for the achievement of good aerosol performance.

\section{MATERIALS AND METHODS}

\section{Materials}

Rifampicin and micronized budesonide (EP) were obtained from Spectrum Chemicals (Gardena, CA, USA). HPLC-grade ethanol and methanol were purchased from Sigma-Aldrich (St. Louis, MO, USA). Samples of anhydrous lactose (SuperTabR 22AN) were supplied by DFE Pharma (formerly DMV-Fonterra, Princeton, NJ, USA). Four separate vendors generously provided size 3 HPMC inhalationgrade capsules: ACGcaps ${ }^{\mathrm{TM}}$ HI (ACG), Embocaps ${ }^{\circledR} \mathrm{VG}$
(Suheung), Vcaps ${ }^{\circledR}$ (Capsugel), and Quali-V® I (Qualicaps). $0.22 \mu \mathrm{m}$ polyethersulfone (PES) syringe filters and Greiner 96 Flat Bottom Transparent Polystyrene (well working volume 25-340 $\mu \mathrm{L}$; total well volume $382 \mu \mathrm{L}$ ) were all obtained from Sigma-Aldrich (St. Louis, MO, USA).

\section{Preparation of Budesonide/Lactose Binary Blends}

Our carrier-based formulation consisted of budesonide and large lactose carrier particles. Through a process of spatulation and geometric dilution, micronized budesonide was combined with inhalation-grade Inhalac 120 lactose in a ratio of 1:50 (w/w), then mixed for $40 \mathrm{~min}$ at $46 \mathrm{rpm}$ with a Turbula ${ }^{\circledR}$ orbital mixer (Glen Mills, Clifton, NJ, USA). The determination of blend uniformity was conducted by evaluating the drug content in the 10 sample powders from each mixture randomly. Formulations were considered to have good uniformity and ready for use if the coefficient of variation $(\% \mathrm{CV})$ between the samples for a given blend was below $5 \%$. The obtained formulations were stored in a desiccator at room temperature.

\section{Preparation of Micronized Rifampicin}

Because of its therapeutic importance for pulmonary lung infections, rifampicin was chosen as a model medication for carrier-free delivery. Rifampicin was milled using a Fluid Energy Model 00 Jet-O-Mizer air jet mill at 75 PSI grind pressure, 65 PSI feed pressure, and $1 \mathrm{~g} / \mathrm{min}$ feed rate to produce particles within the respirable range (27). The obtained formulations were kept in a desiccator at room temperature.

\section{Particle Size Measurement}

A HELOS laser diffractor was used in conjunction with a RODOS dry dispersion device to quantify particle size. During the period when greater than $1 \%$ of the optical concentration was reached, measurements were taken every $5 \mathrm{~ms}$. The Fraunhofer theory was used to solve the article size distribution (PSD). The overall PSD for the sample was calculated by averaging the PSD for each measurement between 5 and $25 \%$ optical concentration. The dispersion pressure was set at 3.0 bar, and the feed table rotation was set at $20 \%$. Only one measurement was taken for each formulation in this study.

\section{Scanning Electron Microscopy (SEM)}

The size and shape of the particles were observed using a scanning electron microscope (Supra 40VP, Zeiss, Germany). Prior to SEM, the powder samples were mounted on aluminum SEM stubs with double-sided carbon tape and sputter-coated with about $20 \mathrm{~nm}$ of platinum/palladium $(\mathrm{Pt} /$ Pd) using a Cressington sputter coater 208 HR under argon (Cresssington Scientific Instruments Ltd., Watford, UK).

\section{In Vitro Drug Deposition}

The aerosol performance of the blended formulations released from each type of capsule was evaluated using a 
Next-Generation Impactor (NGI) and a low-resistance RS01 Monodose Dry Powder Inhaler (RS01 DPI; Plastiape) (5). In the RS01 device, four replicates were done at flow rates comparable to a $4-\mathrm{kPa}$ and $2-\mathrm{kPa}$ pressure drop. The rationale behind selecting pressure drop of $4 \mathrm{kPa}$ and $2 \mathrm{kPa}$ for testing to mimic pressure achievable when a typical adult patient and child patient inhales through an oral DPI, respectively (28). According to USP criteria, the analysis was carried out for long enough to extract $4 \mathrm{~L}$ of air through the NGI, and ran at controlled condition with $25^{\circ} \mathrm{C} / 40 \mathrm{RH}$. For a carrier-based formulation, $20 \mathrm{mg} \pm 2 \mathrm{mg}$ of the formulation was filled each capsule, and 5 capsules were tested in total per replicate to deposit enough of the drug on the NGI stages for analytical analysis beyond the detection limit of the current analytic approach. One capsule was activated per replicate in the carrier-free formulation. By washing with ethanol, eliminating lactose with $0.22 \mathrm{~m}$ PES syringe filters, and quantifying using ultraviolet (UV) spectroscopy at $240 \mathrm{~nm}$, budesonide powder was collected from the inhaler device, mouthpiece adapter, preseparator, induction port, stages 1 to 7 , and the micro-orifice collector (MOC). And by washing the inhaler device, mouthpiece adapter, preseparator, induction port, stages $1-7$, and the micro-orifice collector (MOC) with methanol, deposited rifampicin powder was collected and measured using UV spectroscopy at $340 \mathrm{~nm}$. Ten milliliters of solvent was used to rinse the DPI device and induct port; $5 \mathrm{~mL}$ solvent was used to rinse the adapter and stages 1 to $5 ; 3 \mathrm{~mL}$ solvent was used to rinse stages 6 to 7 and MOC; and $15 \mathrm{~mL}$ solvent was used to rinse the pre-separator if applicable. UV spectroscopy was performed using a Tecan Infinite 200 PRO multimode microplate reader (Tecan Systems, Inc., San Jose, CA, USA). The validation of the UV assay method was confirmed by the value of limit of detection (LOD) $(0.003 \mathrm{mg} / \mathrm{mL}$ for budesonide; $0.002 \mathrm{mg} / \mathrm{mL}$ for rifampicin), and limit of quantification (LOQ) $(0.007 \mathrm{mg} / \mathrm{mL}$ for budesonide; $0.011 \mathrm{mg} / \mathrm{mL}$ for rifampicin). Note that no drug retention has been detected in the syringe filters.

On the basis of the flow rate utilized for each NGI run ( $67 \mathrm{~L} / \mathrm{min}$ or $95 \mathrm{~L} / \mathrm{min}$ ), the cutoff diameters of the NGI from stages 1 to 7 were determined using Eq. 1, and the MOC cutoff diameters were determined using Eq. 2.

$D_{50, Q}=D_{50, Q n}\left(\frac{Q_{n}}{Q}\right)^{x}$

$D_{80, Q}=0.14\left(\frac{Q_{n}}{Q}\right)^{1.36}$

where $D_{50, Q}$ is the cutoff diameter at the flow rate $\mathrm{Q}, D_{50, Q n}$ is the cutoff diameter at the archival reference values of $Q_{n}=$ $60 \mathrm{~L} / \mathrm{min}$, and the values for the exponent, $x$, are taken from Marple et al.(29) about the archival NGI stage cut size-flow rate calculations. The aerosol performance parameters assessed included recovery rate (\%), emitted dose $(E D) /$ emitted fraction $(E F)$, capsule retention dose $(C R D)$ / capsule retention fraction $(C R F)$, respirable fraction $(R F)$ using $5 \mu \mathrm{m}$ or $3 \mu \mathrm{m}$ cutoff size $\left(R F_{<5 \mu \mathrm{m}}, R F_{<3 \mu \mathrm{m}}\right)$, fine particle fraction (FPF) less than $5 \mu \mathrm{m}$ or $3 \mu \mathrm{m}\left(F P F_{<5} \mu \mathrm{m}, F P F_{<3 \mu \mathrm{m}}\right)$, mass median aerodynamic diameter $(M M A D)$, and geometric standard deviation $(G S D)$. As explanation, recovery rate is calculated by the percentage (\%) of drug amount collected from all depositions over the initial loaded drug amount; $E F$ is calculated by the drug mass emitted from the device as a percentage of the total recovered drug mass; $F P F_{<5} \mu \mathrm{m}$ (or $\left.F P F_{<3 \mu \mathrm{m}}\right)$ is calculated by the collected mass less than $5 \mu \mathrm{m}$ (or $3 \mu \mathrm{m}$ ) aerodynamic diameter as a percentage of the emitted drug mass; $R F_{<5 \mu \mathrm{m}}$ (or $R F_{<3 \mu \mathrm{m}}$ ) is calculated by the collected mass less than $5 \mu \mathrm{m}$ (or $3 \mu \mathrm{m}$ ) aerodynamic diameter as a percentage of the total recovered drug mass; MMAD and GSD is calculated by plotting the cumulative percentage of mass as described somewhere else $(29,30)$. Of note, for carrier-based formulation, the calculation is only based on the mass of budesonide itself, instead of the formulation mass.

\section{Capsule Piercing Characteristics}

The pierced capsule pieces (short piece defined as 'cap' while long piece defined as 'body') were collected after device actuation. The pierced zone was examined under the microscope to investigate the presence or absence of attached 'flaps'. Flaps are defined as the remaining material cut but still attached to the capsule wall after the piercing of the capsule. Flap number defined as the number of attached flaps. Another parameter 'the open area' is defined as the pierced area minus the flap area for each capsule piece. Image analysis (ImageJ) was used to quantify the pierced hole openings. For details, the global scale was set first using ruler image to calibrate $1 \mathrm{~mm}$ of the software. Then a polygon selection tool was used to outline the perimeter of capsule hole. By adjusting the threshold of each image, the area inside of the polygon selection can be identified accordingly.

\section{Texture Analysis of DPI Capsules}

The force required for deformation and puncture strength of four HPMC-based capsules were evaluated using a TA-XT2 analyzer (Texture Technologies Corp, New York, USA) along with a 0.5-inch diameter cylindrical, acrylic, 35$\mathrm{mm}$ tall probe (TA-10, Texture Technologies Corp, New York, USA)(31). To determine the force required to deform the capsules, sample capsule shells $(n=5)$ were fixed on a capsule holder to the stand vertically (Fig. 1a). Further, to determine the stiffness of the capsule walls, the capsules were placed on a wider capsule holder to stand horizontally (Fig. 1b). The acrylic probe was distanced $20 \mathrm{~mm}$ above the sample capsule. The test mode was set to compression, with a pretest and test speed of $1 \mathrm{~mm} / \mathrm{s}$, and a posttest speed of $5 \mathrm{~mm} / \mathrm{s}$. The target mode was set to distance, and the distance was set to $8 \mathrm{~mm}$ for the vertical test and $4 \mathrm{~mm}$ for the horizontal test (32). For determining the puncture strength (vertical) $(n=5)$, the puncture needle from the DPI used previously was isolated and fixed on to the acrylic probe (Fig. 1c). The sample capsule was still fixed vertically as shown in Fig. 1c, and the test mode and the protocol for the puncture strength test were maintained the same except for the distance which was reduced to $6 \mathrm{~mm}$ (this corresponded 
to the length of the DPI needle) for the vertical test. The data and graphs were acquired on the Exponent software (Stable Microsystems, Godalming, Surrey, UK).

\section{Statistics}

The data are presented as mean \pm standard deviation and analyzed using ANOVA analysis with post hoc Tukey's multiple comparisons test.

\section{RESULTS}

\section{Characteristics of the Selected Formulation}

In this study, we used budesonide and large lactose carrier particles as our carrier-based formulation. The PSD of the micronized budesonide is shown in Fig. 2a, which has the median diameter (Dv50) of $1.83 \mu \mathrm{m}$, and the Dv50 of Inhalac 120 lactose is $110-115 \mu \mathrm{m}$ (Table I). SEM images showed that budesonide particles were absorbed on the surface of Inhalac 120 lactose after blend (Fig. 3). Because of its therapeutic importance for pulmonary lung infections, rifampicin was chosen as a model medication for carrier-free delivery. The PSD of the milled rifampicin is shown in Fig. 2b, with the Dv50 of $2.45 \mu \mathrm{m}$ (Table I). From the SEM image, it can be seen that the morphology of pure rifampicin changes dramatically before and after micronization, from large crystal to small drug agglomerates (Fig. 3).

\section{In VitroAerosol Performance}

The in vitro aerosol performance of these two formulations delivered from the different four capsules types was evaluated. Standard inhalation performance measures $(E F$, $R F, F P F$, and $M M A D$ ) for each investigated flow rate condition revealed no statistically significant differences between the capsule types for carrier-based budesonide formulation. However, disparities in the variability of these means were discovered (Table II). Using this model formulation, the Quali-V® I capsules had the highest $M M A D$ variability at $2-\mathrm{kPa}$ pressure drop (F test $P<0.05$ ), but the lowest variability at 4-kPa pressure drop (F test $P<0.05)$. At 4-kPa pressure drop under the studied conditions, the variability of ACGcapsTM HI, as well as Embocaps ${ }^{\circledR} \mathrm{VG}$, in terms of RF and FPF, was lower than that of Vcaps ${ }^{\circledR}$ or Quali-V® I (F test $P<0.05)$.

At the $2-\mathrm{kPa}$ pressure drop, statistically significant differences between different capsule types were revealed for $E F$ and $M M A D$ when evaluating the excipient-free rifampicin formulation $(P<0.05)$. ACGcaps ${ }^{\mathrm{TM}} \mathrm{HI}$ and Embocaps ${ }^{\circledR} \mathrm{VG}$ capsules exhibited higher $E F$ and smaller MMADs compared with Vcaps ${ }^{\circledR}$ and Quali-V® I capsules (Table III). For the 4-kPa drop condition, a statistically significant difference was noted in $R F / F P F_{<5} \mu \mathrm{m}$ in between powder-actuated from Embocaps ${ }^{\circledR}$ VG versus ACGcaps ${ }^{\mathrm{TM}}$ HI $(P<0.01)$ and was noted in $\mathrm{RF} / \mathrm{FPF}_{<} 3 \mu \mathrm{m}$ between Embocaps ${ }^{\circledR}$ VG and Quali-V® I $(P<0.05)$ in this study. In addition, the variability of $E F$ at $4-\mathrm{kPa}$ drop condition did differ significantly between ACGcaps ${ }^{\mathrm{TM}} \mathrm{HI}$ or Embocaps ${ }^{\circledR}$ VG and Vcaps ${ }^{\circledR}$ or Quali-V® I (F test $\left.P<0.01\right)$.

\section{In Vitro Deposition Profiles in the NGIs}

Percentage of the nominal dose is shown in Figs. 4 and 5 to reveal the in vitro deposition profiles in the NGIs for drug released by capsules from four different suppliers. In terms of carrier-based formulation, Vcaps ${ }^{\circledR}$ tended to retain the drug significantly from the tested formulations in both 4-kPa and 2$\mathrm{kPa}$ pressure drop conditions, while the powder actuated from Quali-V® I showed significantly greater deposition in inhaler adapter at lower pressure drop condition (Fig. 4). When considering carrier-free formulation, rifampicin was found to have a significantly greater deposition in induction port when delivered from Embocaps ${ }^{\circledR} \mathrm{VG}$ at the $2-\mathrm{kPa}$ pressure drop or ACGcaps ${ }^{\mathrm{TM}} \mathrm{HI}$ at 4-kPa pressure drop, but less deposition in stage 1 compared with Quali-V® I and Vcaps ${ }^{\circledR}$ if emitted by Embocaps ${ }^{\circledR}$ VG or ACGcaps ${ }^{\text {TM }} \mathrm{HI}$ at the 2-kPa pressure drop (Fig. 5).

\section{Capsule Piercing Characteristics}

Furthermore, we investigated the capsule piercing difference under the microscope (Fig. 6). Similar to the cascade impaction-based metrics for aerosol performance when using the carrier-based model, there were no statistically significant changes between the open areas after the device pierced the capsule, yet there appeared to be differences in the variability of the piercing across different capsule types (Table IV).

Interestingly, Quali-V® I capsules, which exhibited the most variability in MMAD at the 2-kPa pressure drop among the capsules studied, also had the most variability in an open area following piercing ( $\mathrm{F}$ test $P<0.05)$. The same trend was also noted in ACGcaps ${ }^{\mathrm{TM}} \mathrm{HI}$ at $4-\mathrm{kPa}$ pressure drop, indicating that there is a potential link between the variability of MMAD and capsule open area after piercing. No such relationship was noted with the carrier-free formulation. Instead, the amount of free space accessible for powder escape following device piercing varied greatly between capsule makers. In particular, Quali-V® I capsules appeared to exhibit a pressure drop dependency on the pierced hole area, with the lower pressure drop condition resulting in the smallest open area among the capsules tested and the higher pressure drop condition resulting in the highest open area among the capsules though it is unclear if the two variables are mechanistically linked (Table IV). Since the piercing needle is the same at each experiment, one explanation for these pressure drop-related features can be the differences in the composition of the different capsule suppliers that the increasing pressure drop may contribute to the detachment of the capsule flaps after piercing depending on the capsule composition.

Lastly, the 'capsule flaps' may be of importance to the aerosol performance of drug/formulation powders (33). After piercing, a flap may attach to the capsule shell and can be perpendicular to the pierced opening (Fig. 6). Alternatively, the flap may return to its original position after the DPI device pin leaves capsule. Lastly, the piercing may remove the flap entirely. Furthermore, during airflow through the device upon testing with the NGI, it is possible that the flap becomes detached due to the turbulent flow, shear, or capsule collisions. In Table $\mathrm{V}$, we quantified the flap number difference among the four capsule types. In general, flaps of 
a)

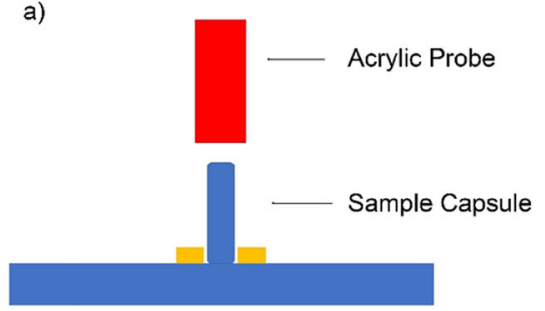

b)

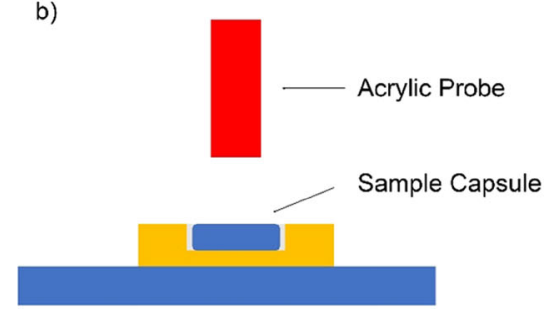

c)

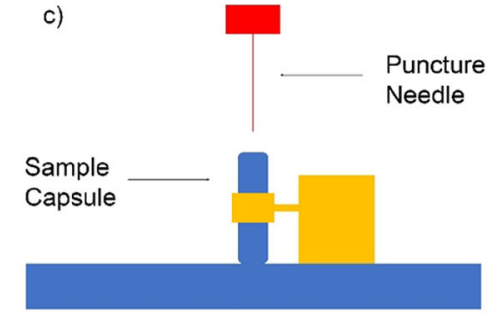

Fig. 1. Schematics of the a vertical deformation methodology, b horizontal press methodology, and $\mathbf{c}$ vertical puncture test

Vcaps ${ }^{\circledR}$, which were observed to be attached to the capsule before NGIs, but were observed to detach more frequently than other capsules after NGIs testing at two pressure drop conditions in this study. Quali-V® I has the largest flap number at lower pressure drop condition. Notably, the flap number of ACGcaps ${ }^{\mathrm{TM}} \mathrm{HI}$ capsules seems to remain similar under the different pressure drop conditions. Similar trends were noted for different formulations used in this study.

\section{Texture Analysis DPI Capsules}

All capsules observed two deformation points on the application of force (Fig. 7a). The first deformation was due to the inner shell (directly in contact with the probe), which can be used for estimating the hardness of the entire capsule, and the second was due to the outer shell. The average force contributing to each of the mentioned deformations are depicted in Table VI. ANOVA results among the capsule groups for the first deformation and the second deformation were observed to have a significant difference. On conducting post hoc test, it was noted that the mean scores of ACGcaps $^{\mathrm{TM}} \mathrm{HI}(M=627.63, S D=29.04)$, Vcaps ${ }^{\circledR}(M=$ $640.60, S D=26.51)$, and Quali-V® $\mathrm{I}(M=627.63, S D=$ 29.04) were not different from one another but were significantly higher than that of Embocaps ${ }^{\circledR}$ VG $(M=$ $415.68, S D=29.04$ ) for the first deformation force, indicating that Embocaps ${ }^{\circledR}$ VG capsules have the smallest entire capsule hardness among others. Although ACGcaps ${ }^{\mathrm{TM}} \mathrm{HI}$ $(M=1681.42, S D=45.99), \operatorname{Vcaps}{ }^{\circledR}(M=1617.88, S D=$ 41.98), and Embocaps ${ }^{\circledR}$ VG $(M=1811.20, S D=45.99)$ were found to be significantly different from Quali-V® ${ }^{\circledR}(M=$ 1405.83, $S D=45.99)$; moreover, Embocaps ${ }^{\circledR}$ VG $(M=$ 1811.20, $S D=45.99)$ and Vcaps ${ }^{\circledR}(M=1617.88, S D=$ 41.98) were also significantly different in terms of the second deformation force; unlike the first deformation, this may not provide us with useful information regarding the capsule characteristics, since the second deformation occurs due to a multitude of variables and cannot be considered as a reliable source of texture.

Furthermore, we calculated the stiffness based on the horizontal stiffness test. Stiffness is the resistance to deformation (i.e., the area under the curve before the first deformation hence the unit $(\mathrm{g} * \mathrm{~mm})$ ) (Fig. $7 \mathrm{~b})$. As the result shown in Table VI, Embocaps ${ }^{\circledR}$ VG capsules exhibited the highest stiffness $(5677.5 \pm 360.4)$, followed by Quali-V® I capsule, whereas Quali-V® I had the lowest values (4805.1 \pm 189.5).

Next, we evaluated the puncture strengths for each type of capsules on the vertical direction, to reflect the hardness of the domes and body of the capsule separately. Vertically, we found that the force required by the needle is the least in the Vcaps ${ }^{\circledR}$ capsule group (Fig. 7c). The post hoc analysis revealed that the mean scores of ACGcaps ${ }^{\mathrm{TM}} \mathrm{HI}(M=$ 319.11, $S D=14.03)$, Quali-V® I $(M=319.11, S D=14.03)$, and Embocaps ${ }^{\circledR}$ VG $(M=315.13, S D=14.03)$ were not significantly different from one another but were significantly different from Vcaps ${ }^{\circledR}(M=234.89, S D=12.81)$ (Table VI), indicating the domes of $\mathrm{Vcaps}{ }^{\circledR}$ capsules had the lowest hardness.
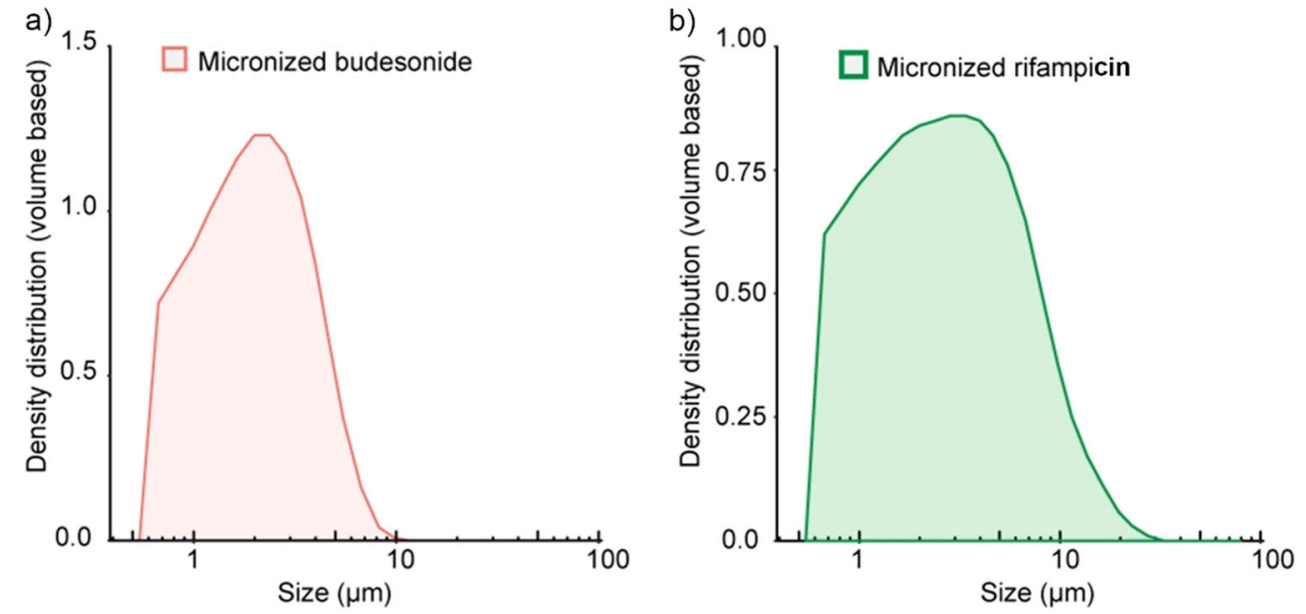

Fig. 2. Particle size distribution $(>0.5 \mu \mathrm{m})$ of miconized a) budesonide and b) rifampicin under 3 bar dispersion pressure 
Table I. Size Distribution ( $>0.5 \mu \mathrm{m})$ of Micronized Drug Formulations and Carriers

\begin{tabular}{llll}
\hline Materials & Dv10 $(\mu \mathrm{m})$ & Dv50 $(\mu \mathrm{m})$ & Dv90 $(\mu \mathrm{m})$ \\
\hline Micronized rifampicin & 0.75 & 2.45 & 7.93 \\
Micronized budesonide & 0.72 & 1.83 & 4.17 \\
Inhalac 120 lactose (specifications from manufacturer) & $70-105$ & $110-115$ & $160-215$ \\
\hline
\end{tabular}

\section{DISCUSSION}

The original dry powder inhalers (DPIs) were singledose devices with the powder formulation in a gelatin capsule, which were introduced in the 1970s. Despite 50 years of DPIs, and the continuing use of capsule-based devices, there have been relatively few studies focusing on inhalation capsules in peer-reviewed literature. In this study, by the comparison of four commercial size 3 HPMC inhalationgrade capsules on aerosol performance with two model DPI formulations, we found that for the model formulation that contained drug only (i.e. rifampicin) in this study, the capsule type influenced $E F, R F, F P F$, and $M M A D$. Embocaps ${ }^{\circledR} \mathrm{VG}$ was observed to have the best aerosol performance. It had greater EF at the lower pressure drop and showed promising $R F / F P F$ data at $4-\mathrm{kPa}$ pressure drop testing in this study. With greater $E F$, more of the drug payload is delivered out of the capsule and the device, potentially indicating better fluidization, while improved $R F / F P F$ correlates to improved deaggregation and more drugs going into the patients' deep
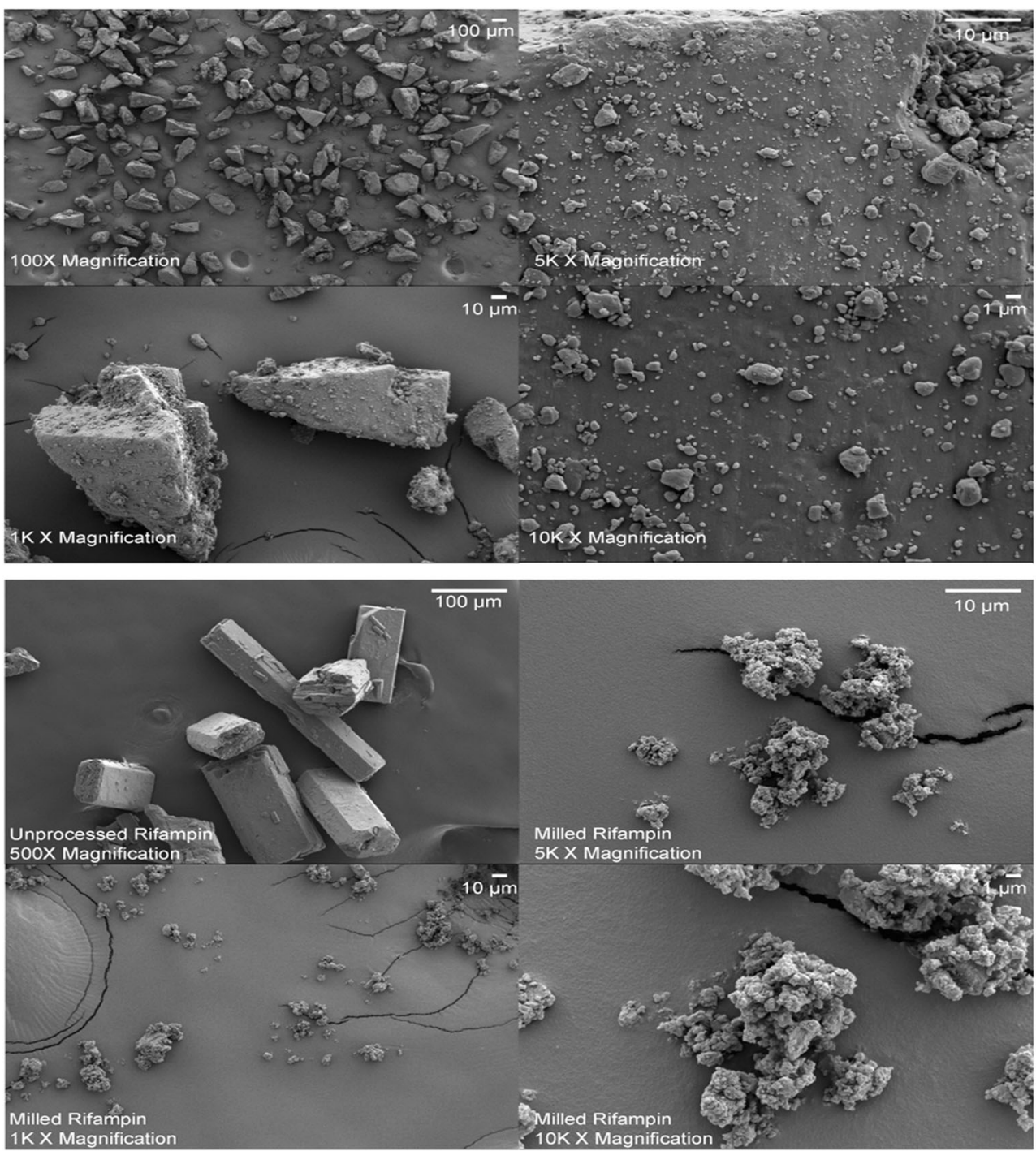

Fig. 3. Top image shows carrier-based formulation (Budesonide + Lactose) under $100 \times, 1000 \times, 5000 \times$, and $10,000 \times$ magnification; bottom image shows carrier-free formulatiom (Rifampicin pure drug) under $100 \times, 1000 \times$, $5000 \times, 10,000 \times$ magnification 
Table II. Aerosol Performance Parameters for Budesonide Formulations with Inhalac 120 Lactose Carrier Particles Characterized In Vitro from Embocaps ${ }^{\circledR}$ VG, Vcaps ${ }^{\circledR}$, Quali-V® ${ }^{\circledR}$, and ACG $^{\mathrm{TM}}$ HI Capsules at 2-kPa and 4-kPa Drop Condition. Values are Given as the Mean \pm Standard Deviation of $N=4$ Replicates $\left(* P<0.05, * * P<0.01\right.$, All Compared with the Vcaps ${ }^{\circledR}$ Group)

\begin{tabular}{|c|c|c|c|c|c|c|c|c|}
\hline \multirow[t]{2}{*}{ Capsules types } & \multicolumn{2}{|c|}{ Embocaps ${ }^{\circledR}$ VG } & \multicolumn{2}{|l|}{ Vcaps ${ }^{\circledR}$} & \multicolumn{2}{|c|}{ Quali-V® I } & \multicolumn{2}{|c|}{ ACGCAPS ${ }^{\mathrm{TM}} \mathrm{HI}$} \\
\hline & $2 \mathrm{kPa}$ & $4 \mathrm{kPa}$ & $2 \mathrm{kPa}$ & $4 \mathrm{kPa}$ & $2 \mathrm{kPa}$ & $4 \mathrm{kPa}$ & $2 \mathrm{kPa}$ & $4 \mathrm{kPa}$ \\
\hline Recovery rate (\%) & $85.5 \pm 5.2$ & $85.2 \pm 3.9$ & $80.8 \pm 2.6$ & $80.8 \pm 4.6$ & $92.5 \pm 5.4$ & $85.6 \pm 3.4$ & $94.8 \pm 13.8$ & $85.2 \pm 7.2$ \\
\hline Emitted dose (mg) & $1.3 \pm 0.1$ & $1.4 \pm 0.1$ & $1.2 \pm 0.1$ & $1.2 \pm 0.1$ & $1.4 \pm 0.2$ & $1.4 \pm 0.1$ & $1.4 \pm 0.2$ & $1.4 \pm 0.1$ \\
\hline Emitted fraction (\%) & $79.7 \pm 2.9$ & $84.0 \pm 2.6$ & $78.9 \pm 1.3$ & $80.5 \pm 4.1$ & $82.6 \pm 4.1$ & $87.4 \pm 3.8$ & $77.6 \pm 3.4$ & $86.0 \pm 5.1$ \\
\hline Capsule retention dose (mg) & $0.3 \pm 0.1 *$ & $0.1 \pm 0.2 *$ & $0.6 \pm 0.5$ & $0.6 \pm 0.3$ & $0.4 \pm 0.3$ & $0.4 \pm 0.2 *$ & $0.3 \pm 0.2 *$ & $0.3 \pm 0.4$ \\
\hline Capsule retention fraction (\%) & $1.4 \pm 0.7 *$ & $0.6 \pm 0.9 *$ & $2.9 \pm 2.2$ & $3.0 \pm 1.4$ & $2.2 \pm 1.4$ & $1.8 \pm 0.9 *$ & $1.7 \pm 0.9 *$ & $1.6 \pm 1.8$ \\
\hline$R F<5 \mu \mathrm{m}(\%)$ & $7.8 \pm 1.0$ & $12.4 \pm 0.6$ & $9.6 \pm 2.2$ & $11.0 \pm 2.4$ & $8.9 \pm 2.7$ & $12.9 \pm 2.6$ & $8.4 \pm 1.2$ & $11.4 \pm 0.4$ \\
\hline$R F<3 \mu \mathrm{m}(\%)$ & $5.8 \pm 0.9$ & $9.7 \pm 0.5$ & $7.3 \pm 1.6$ & $8.6 \pm 1.8$ & $7.0 \pm 2.0$ & $10.3 \pm 2.0$ & $6.2 \pm 1.1$ & $9.4 \pm 0.6$ \\
\hline$F P F<5 \mu \mathrm{m}(\%)$ & $9.8 \pm 1.5$ & $14.8 \pm 0.6$ & $12.2 \pm 2.8$ & $13.7 \pm 2.7$ & $10.9 \pm 3.7$ & $14.9 \pm 3.4$ & $10.8 \pm 1.4$ & $13.3 \pm 1.1$ \\
\hline$F P F<3 \mu \mathrm{m}(\%)$ & $7.3 \pm 1.3$ & $11.5 \pm 0.6$ & $9.3 \pm 2.0$ & $10.6 \pm 2.0$ & $8.6 \pm 2.8$ & $11.8 \pm 2.6$ & $8.0 \pm 1.3$ & $11 \pm 0.3$ \\
\hline$M M A D(\mu \mathrm{m})$ & $3.7 \pm 0.2$ & $3.3 \pm 0.2$ & $3.5 \pm 0.2$ & $3.4 \pm 0.1$ & $3.4 \pm 0.7$ & $3.2 \pm 0.1$ & $3.7 \pm 0.2$ & $3.0 \pm 0.3$ \\
\hline$G S D$ & $1.3 \pm 0.1$ & $1.3 \pm 0.1$ & $1.2 \pm 0.0$ & $1.3 \pm 0.1$ & $1.3 \pm 0.2$ & $1.3 \pm 0.1$ & $1.2 \pm 0.1$ & $1.3 \pm 0.1$ \\
\hline
\end{tabular}

$R F$, respirable fraction; FPF, fine particle fraction; MMAD, mass median aerodynamic diameter; GSD, geometric standard deviation

lungs after inhalation. As mentioned above, the advantage of Embocaps ${ }^{\circledR}$ VG capsule on $E F$ may be attributed to the outstanding hardness of the entire capsule among all capsules. In fact, good $R F / F P F$ may also result from superior hardness. It has been found that the capsule hardness is one component that regulates the powder dispersion by controlling the collision velocity between the capsule and inhaler walls (34). A significant impaction force is generated when the capsule collides with the capsule chamber wall at a high collision speed and frequency, which aids powder dispersion (35). Softness in capsules, on the other hand, can buffer a portion of the impact force, lowering the capsule motion's velocity. As a result, the capsule chamber's collision frequency is reduced, and the capsule velocity is altered (34). In addition, the stiffness of the capsule shell can be translated to the ease of shock transfer, as stiffer materials transfer shock faster whereas flexible materials tend to absorb the shock, thereby delaying the shock transfer and reducing the intensity of the shock $(36,37)$. From this relationship, stiffer capsules such as Embocaps ${ }^{\circledR}$ VG should aid powder desegregation, thereby depicting a better performance. Further examination of capsule piercing revealed that, despite major differences among capsule makers, there appeared to be no effect on aerosol performance with this formulation.

Budesonide formulation dispersed from different capsules had no significant difference between measurements of aerosol performance but did show trends in variability. These variability in aerosol performance can originate from various sources including the variation of the formulations, environment, and the capsule used in the study. In terms of capsule aspect, quality variability caused by manufacturing processing (38), capsule storage (18), and muptile capsules used for per NGI testing due to the detection limitation of the analytic method used in this study for budesonide. Differences in aerosol performance variability may have significant implications for in vivo performance and pharmacological efficacy,

Table III. Aerosol Performance Parameters for Rifampicin Formulations Characterized In Vitro from ACGcaps ${ }^{\mathrm{TM}}$ HI, Embocaps ${ }^{\circledR}$ VG, Vcaps ${ }^{\circledR}$, and Quali-V® I capsules at 2-kPa and 4-kPa Drop Conditions. Values are Given as the Mean \pm Standard Deviation of $N=4$ Replicates $\left({ }^{\mathbf{\Lambda}} P<0.05,{ }^{\mathbf{\Lambda}} P<0.01\right.$; All compared with the Embocaps ${ }^{\circledR}$ VG Group)

\begin{tabular}{|c|c|c|c|c|c|c|c|c|}
\hline \multirow[t]{2}{*}{ Capsules types } & \multicolumn{2}{|c|}{ Embocaps ${ }^{\circledR}$ VG } & \multicolumn{2}{|l|}{ Vcaps $®$} & \multicolumn{2}{|l|}{ Quali-V® I } & \multicolumn{2}{|c|}{ ACGCAPSTм HI } \\
\hline & $2 \mathrm{kPa}$ & $4 \mathrm{kPa}$ & $2 \mathrm{kPa}$ & $4 \mathrm{kPa}$ & $2 \mathrm{kPa}$ & $4 \mathrm{kPa}$ & $2 \mathrm{kPa}$ & $4 \mathrm{kPa}$ \\
\hline Recovery rate (\%) & $89.5 \pm 6.2$ & $88.8 \pm 2.2$ & $86.2 \pm 4.4$ & $87.3 \pm 4.5$ & $85.3 \pm 4.5$ & $85.8 \pm 5.6$ & $85.3 \pm 1.0$ & $86.9 \pm 2.3$ \\
\hline Emitted dose (mg) & $15.6 \pm 0.9$ & $16.3 \pm 0.3$ & $15.1 \pm 1.2^{\mathbf{\Delta}}$ & $15.5 \pm 0.4$ & $15.1 \pm 1.3^{\boldsymbol{\Delta}}$ & $15.0 \pm 0.7$ & $14.2 \pm 0.6$ & $16.5 \pm 0.5$ \\
\hline Emitted fraction (\%) & $89.9 \pm 1.7$ & $93.5 \pm 0.5$ & $85.5 \pm 2.6^{\mathbf{\Lambda}}$ & $90.3 \pm 2.7$ & $85.0 \pm 1.9^{\boldsymbol{\Lambda}}$ & $88.6 \pm 3.8$ & $86.5 \pm 1.9$ & $92.6 \pm 0.7$ \\
\hline Capsule retention dose (mg) & $0.3 \pm 0.2$ & $0.3 \pm 0.2$ & $0.7 \pm 0.3$ & $0.9 \pm 0.5$ & $0.8 \pm 0.4$ & $1.0 \pm 0.6$ & $0.5 \pm 0.2$ & $0.4 \pm 0.1$ \\
\hline Capsule retention fraction (\%) & $1.8 \pm 1.1$ & $1.5 \pm 0.8$ & $3.3 \pm 1.2$ & $4.7 \pm 2.7$ & $3.7 \pm 2.1$ & $5.1 \pm 2.5$ & $2.8 \pm 1.3$ & $2.0 \pm 0.5$ \\
\hline$R F<5 \mu \mathrm{m}(\%)$ & $45.0 \pm 4.6$ & $49.2 \pm 2.7$ & $43.7 \pm 1.8$ & $42.2 \pm 5.6^{\boldsymbol{\Lambda}}$ & $40.9 \pm 4.8$ & $43.6 \pm 3.2^{\boldsymbol{\Lambda}}$ & $45.0 \pm 4.4$ & $38.9 \pm 4.6^{\boldsymbol{\Lambda}}$ \\
\hline$R F<3 \mu \mathrm{m}(\%)$ & $30.0 \pm 5.5$ & $33.1 \pm 2.8$ & $26.0 \pm 1.4$ & $25.9 \pm 5.1^{\wedge}$ & $25.9 \pm 3.5$ & $28.2 \pm 2.5^{\boldsymbol{\Lambda}}$ & $28.1 \pm 4.2$ & $25.1 \pm 3.3^{\boldsymbol{\Lambda}}$ \\
\hline$F P F<5 \mu \mathrm{m}(\%)$ & $50.1 \pm 5.3$ & $52.6 \pm 3.0$ & $51.1 \pm 3.1$ & $46.7 \pm 5.3^{\boldsymbol{\Lambda}}$ & $48.1 \pm 5.4$ & $49.2 \pm 3.1^{\boldsymbol{\Lambda}}$ & $51.96 \pm 4.55$ & $41.99 \pm 3.2^{\mathbf{\Lambda}}$ \\
\hline$F P F<3 \mu \mathrm{m}(\%)$ & $33.5 \pm 6.4$ & $35.4 \pm 3.1$ & $30.4 \pm 2.1$ & $28.6 \pm 5.1^{\wedge}$ & $30.5 \pm 4.2$ & $31.8 \pm 2.0^{\wedge}$ & $32.5 \pm 4.5$ & $27.1 \pm 3.3^{\mathbf{\Lambda}}$ \\
\hline$M M A D(\mu \mathrm{m})$ & $4.2 \pm 0.5$ & $4.3 \pm 0.3$ & $5.1 \pm 0.2^{\boldsymbol{\Lambda}}$ & $5.3 \pm 1.0$ & $5.1 \pm 0.3^{\boldsymbol{\Lambda}}$ & $4.9 \pm 0.6$ & $4.5 \pm 0.5$ & $4.6 \pm 0.7$ \\
\hline$G S D$ & $1.4 \pm 0.0$ & $1.4 \pm 0.0$ & $1.4 \pm 0.0$ & $1.5 \pm 0.0$ & $1.4 \pm 0.0$ & $1.4 \pm 0.1$ & $1.4 \pm 0.0$ & $1.4 \pm 0.0$ \\
\hline
\end{tabular}

$R F$, respirable fraction; FPF, fine particle fraction; MMAD, mass median aerodynamic diameter; GSD, geometric standard deviation 


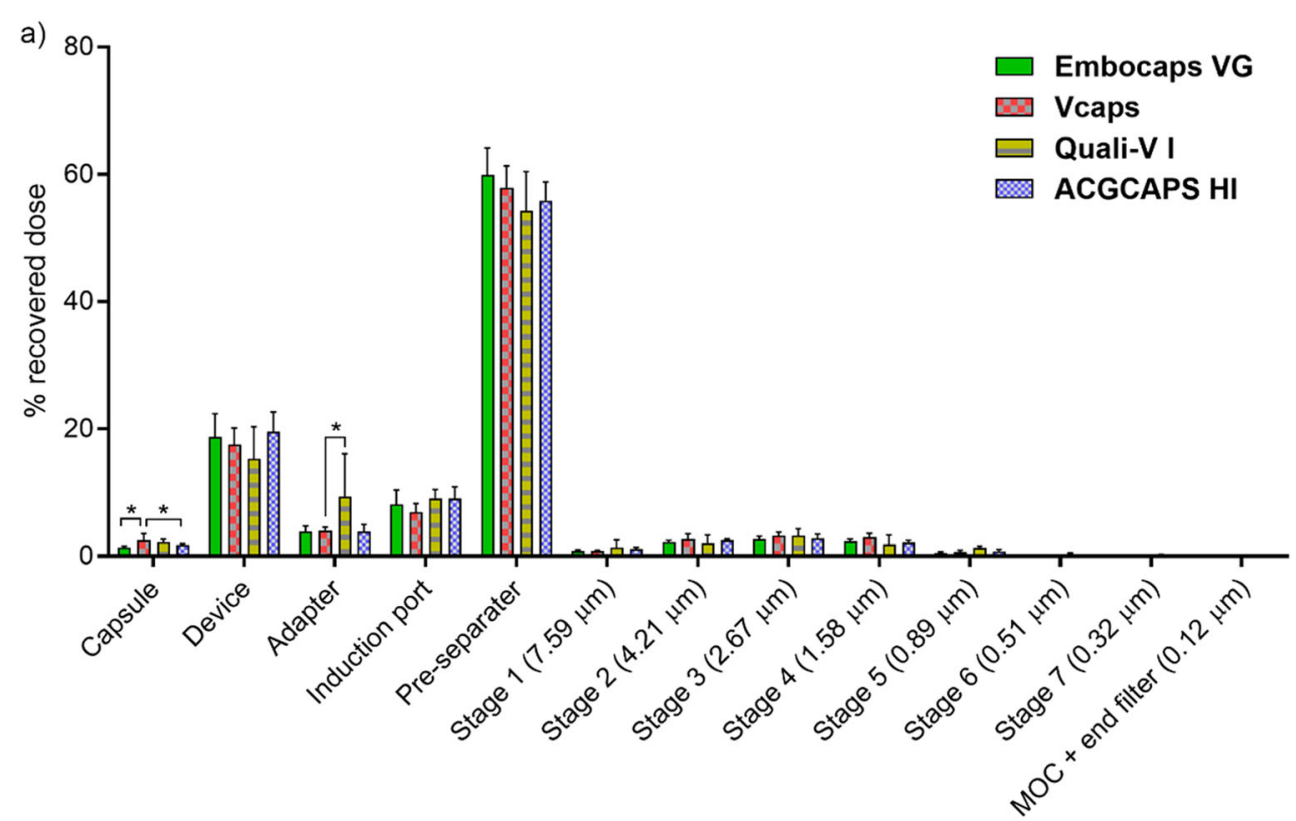

b)

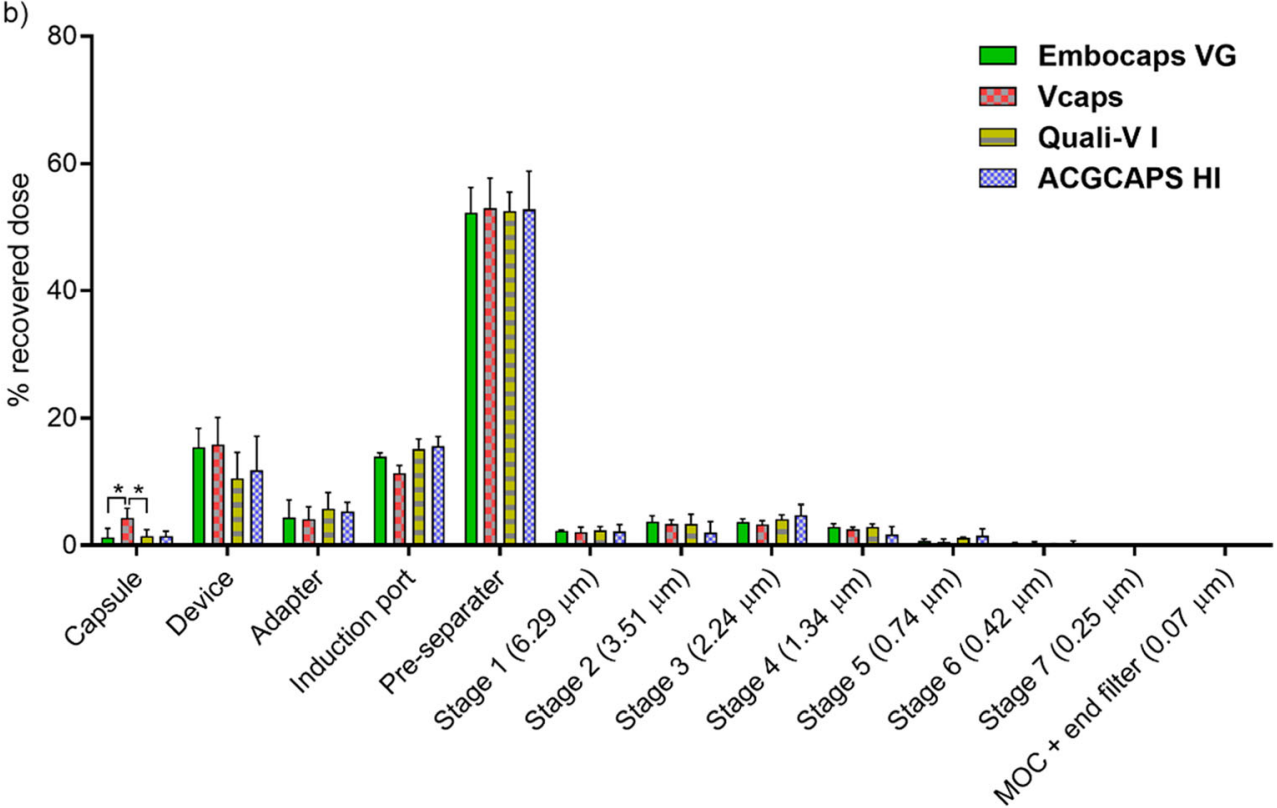

Fig. 4. Deposition of budesonide actuated from Embocaps ${ }^{\circledR}$ VG (Suheung), Vcaps ${ }^{\circledR}$ (Capsugel), QualiV® I (Qualicaps), and ACGcaps ${ }^{\mathrm{TM}} \mathrm{HI}$ (ACG) in different NGI stages at 2-kPa (a) and 4-kPa (b) pressure drop conditions. Data are shown as the mean \pm standard deviation and analyzed by ANOVA analysis with post hoc Tukey's multiple comparison test. $* P<0.05, * * P<0.01, N=4$ replicates

especially for very powerful medications where consistency of administration is critical (39). Quali-V® I had larger variability in $M M A D$ at lower pressure drop and conversely had smaller variability at high-pressure drop in this budesonide formulation study. This indicates greater consistency in aerodynamic diameters at a higher pressure drop in QualiV® I capsule for budesonide formulations. ACGcaps ${ }^{\mathrm{TM}} \mathrm{HI}$ as well as Embocaps ${ }^{\circledR}$ VG also showed less variability in RF and FPF at the higher 4-kPa pressure drop for budesonide formulations. The trend showed that for budesonide formulations, there is a correlation between pressure drop condition and precision of aerosol performance, with higher pressure producing higher aerosol performance precision. Depending on the application and the product being developed, differences in the in vitro deposition profiles similar to those observed in these studies may become important in the selection of a capsule for a particular formulation. For example, based on the in vitro deposition profile, Vcaps ${ }^{\circledR}$ showed the most retention of the drug in the capsule after NGI, while Embocaps ${ }^{\circledR} \mathrm{VG}$ showed the least for the budesonide-lactose formulation tested here. This can be correlated by the hardness of the capsule since Embocaps ${ }^{\circledR}$ VG capsule also showed the most hardness of the entire capsule in our study, and Vcaps ${ }^{\circledR}$ capsule was softer. The 

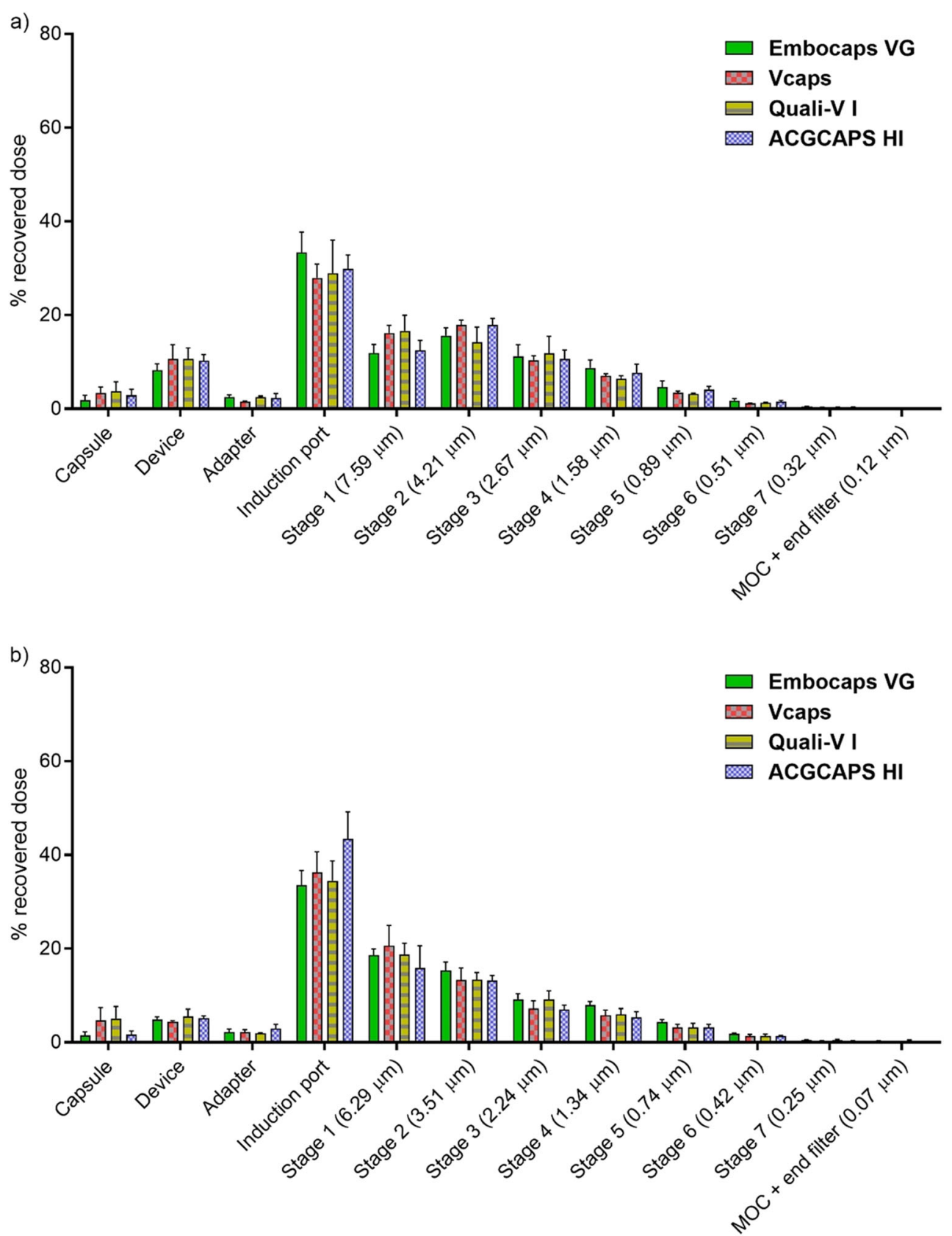

Fig. 5. Deposition of rifampicin actuated from Embocaps ${ }^{\circledR}$ VG (Suheung), Vcaps ${ }^{\circledR}$ (Capsugel), Quali-V® I (Qualicaps), and ACGcaps ${ }^{\mathrm{TM}} \mathrm{HI}$ (ACG) in different NGI stages at 2-kPa (a) and 4-kPa (b) drop conditions. Data are shown as the mean \pm standard deviation and analyzed by ANOVA analysis with post hoc Tukey's multiple comparison test. $* P<0.05$, ${ }^{*} P<0.01, N=4$ replicates

hardness of the entire capsule can contribute to the drug/ formulation powder release in two different aspects. Firstly, the high velocity of capsule-inhaler wall collisions help powder de-agglomerate(40, 41). On the other hand, the collisions may cause a capsule with less stiffness or hardness to be more easily deformed during powder release from the system. Less momentum transfer during the capsule-device collisions will be transferred to the powder within the capsule when softer, less rigid materials are used. Previously, we showed that momentum transfer events between particles within DPIs is important for aerosol performance (5). Therefore, the capsule physical and chemical factors can play a significant role in determining aerosol performance. Additionally, differences in the physicochemical properties of the dry powder formulations utilized in this study may have resulted in differences when comparing the aerosol performance of the capsules. As evidenced by the differences in dispersion efficiency between the carrier-based budesonide formulations (between 10 and 15\% FPF) and the carrier-free rifampicin formulations (between 30 and $40 \%$ FPF), the formulations tested had different levels of dispersibility. Small changes in capsule performance were unlikely to significantly modify the performance of the carrier-based budesonide formulations which were characterized by high degrees of 

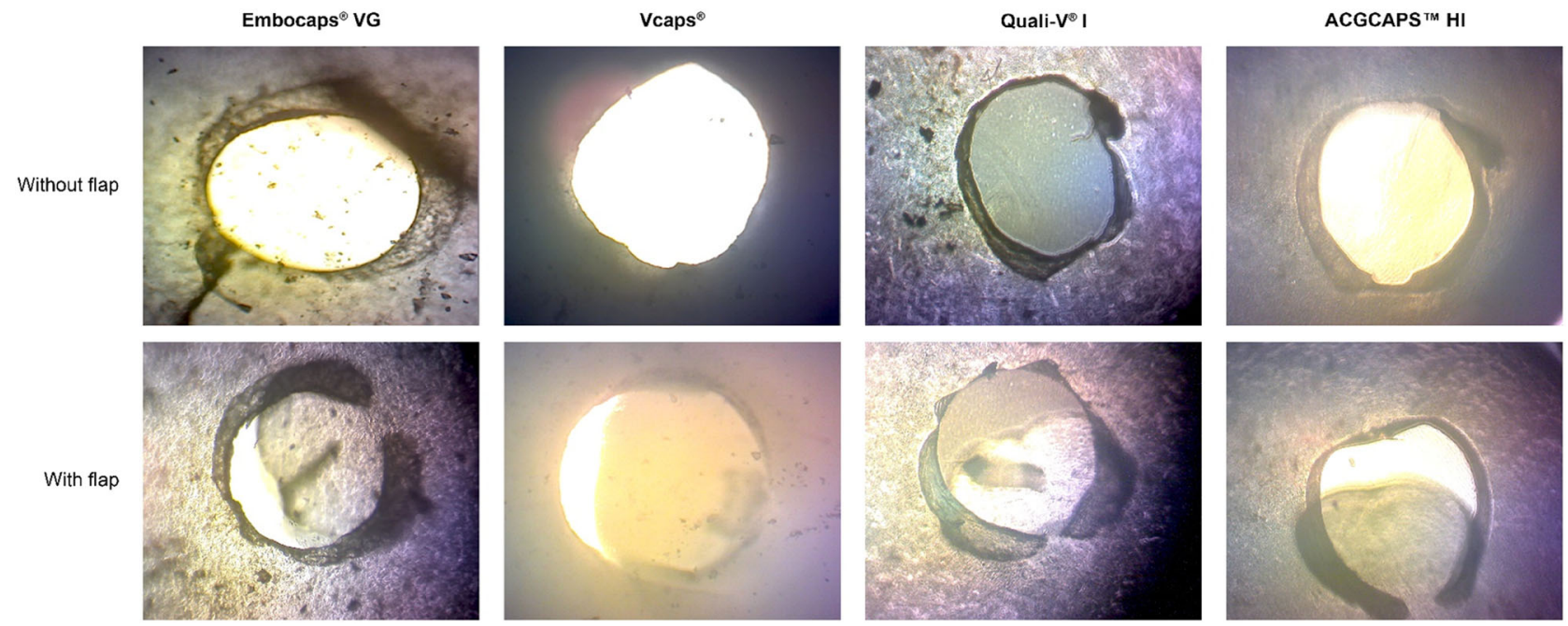

Fig. 6. Representative microscope images of the pierced openings of capsule shells from different capsule suppliers (Embocaps ${ }^{\circledR}$ VG (Suheung), Vcaps ${ }^{\circledR}$ (Capsugel), Quali-V® I (Qualicaps), and ACGcaps ${ }^{\mathrm{TM}}$ HI (ACG)) with or without flap

adhesiveness. In contrast, the carrier-free rifampicin formulations, which was more easily dispersed, may reveal the influence of small changes in capsule properties in the aerosol performance data.

Of note, in the case of our carrier-free rifampicin formulation, $E F$ is not significantly different at $4 \mathrm{kPa}$ between Embocaps ${ }^{\circledR}$ VG and ACGcaps ${ }^{\mathrm{TM}} \mathrm{HI}$, but there is a significant difference in the $F P F$, which was unexpected considering that the same formulation at the same pressure drop was tested. The differences in FPF may be due to the underlying mechanisms of powder emission (fluidization and entrainment) differing from the mechanisms of dispersion (deaggregation of the entrained powder) (19, 42, 43). Thus, even though $E F$ is not different between selected capsule types, $F P F$ can be different. $E F$ is determined by the collision with the inhaler walls and internal structures, as well as the powder charging that affects the powder detachment from capsule wall surfaces; in addition, entrainment in the airflow is required; but for $F P F$, only deaggregation caused by powder-device interactions of sufficient energy can contribute to it for exactly the same formulation at the same pressure drop.
Based on our data, by comparing the aerosol performance between formulation, it is obvious that different conclusion about the effect of capsule types on powder aerosol performance can be obtained from different formulation cases. For example, $E D$ takes into account the amount of drug emitted from both the capsule and the device, and the device retention is much lower for carrier free as compared with carrierbased formulation, but within the same formulation, there is no difference based on the changes in the pressure drop. This suggests that the energy of collisions and subsequent deaggregation may overcome to a greater extent the cohesive particle-particle interactions in the carrier-free formulation which may be weaker than the adhesive drug-carrier forces in the carrier-based formulations. Based on our data, it may be worth to draw the conclusion that formulation type and capsule property are interdependent on aerosol performance. Moreover, formulation type has a larger impact than capsule property for powder aerosol performance. However, studies with other carrier-based/ carrier-free formulations may be necessary to assess the relationship of formulation differences with capsule properties on aerosol performance.

In the examination of capsule piercing, in the case of carrier-based formulation, though no significant differences in the size of the pierced hole in a different capsule as well, the

Table IV. Open Area Difference After Piercing Capsules for Carrier-Based Budesonide Formulations and Carrier-Free Rifampicin Formulations Characterized from ACGcaps ${ }^{\mathrm{TM}}$ HI, Embocaps ${ }^{\circledR}$ VG, Vcaps ${ }^{\circledR}$, and Quali-V® I Capsules at 2-kPa and 4-kPa Drop Conditions. Values are Given as the Mean \pm Standard Deviation of $N=20$ Replicates for Carrier-Based Budesonide Formulations and $N=4$ for CarrierFree Rifampicin Formulations $\left({ }^{*} P<0.05,{ }^{\infty} P<0.01\right.$; All Compared with the Quali-V® I Group)

\begin{tabular}{|c|c|c|c|c|c|c|c|c|c|}
\hline \multirow[t]{2}{*}{ Capsules types } & & \multicolumn{2}{|c|}{ Embocaps $®$ VG } & \multicolumn{2}{|l|}{ Vcaps ${ }^{\circledR}$} & \multicolumn{2}{|c|}{ Quali-V® I } & \multicolumn{2}{|c|}{ ACGCAPS ${ }^{\mathrm{TM}} \mathrm{HI}$} \\
\hline & & $2 \mathrm{kPa}$ & $4 \mathrm{kPa}$ & $2 \mathrm{kPa}$ & $4 \mathrm{kPa}$ & $2 \mathrm{kPa}$ & $4 \mathrm{kPa}$ & $2 \mathrm{kPa}$ & $4 \mathrm{kPa}$ \\
\hline \multirow[t]{2}{*}{ Cap open area after piercing $\left(\mathrm{mm}^{2}\right)$} & Carrier-based & $1.6 \pm 0.1$ & $1.4 \pm 0.1$ & $1.6 \pm 0.1$ & $1.5 \pm 0.2$ & $1.9 \pm 0.6$ & $1.7 \pm 0.2$ & $1.7 \pm 0.3$ & $1.9 \pm 0.4$ \\
\hline & Carrier-free & $1.7 \pm 0.1$ & $1.6 \pm 0.1$ & $1.8 \pm 0.2$ & $1.6 \pm 0.1$ & $1.6 \pm 0.0$ & $1.7 \pm 0.2$ & $1.6 \pm 0.0$ & $1.7 \pm 0.2$ \\
\hline \multirow[t]{2}{*}{ Body open area after piercing $\left(\mathrm{mm}^{2}\right)$} & Carrier-based & $1.7 \pm 0.2$ & $1.5 \pm 0.2$ & $1.2 \pm 0.3$ & $1.6 \pm 0.1$ & $1.6 \pm 0.3$ & $1.6 \pm 0.1$ & $1.6 \pm 0.1$ & $1.9 \pm 0.3$ \\
\hline & Carrier-free & $1.6 \pm 0.1$ & $1.5 \pm 0.1$ & $1.7 \pm 0.2$ & $1.6 \pm 0.1$ & $1.5 \pm 0.2$ & $1.6 \pm 0.1$ & $1.4 \pm 0.3$ & $1.9 \pm 0.3$ \\
\hline \multirow[t]{2}{*}{ Total open area after piercing $\left(\mathrm{mm}^{2}\right)$} & Carrier-based & $3.3 \pm 0.2$ & $2.9 \pm 0.3$ & $2.8 \pm 0.4$ & $3.1 \pm 0.4$ & $3.3 \pm 0.9$ & $3.3 \pm 0.3$ & $3.3 \pm 0.4$ & $3.5 \pm 0.7$ \\
\hline & Carrier-free & $3.3 \pm 0.18$ & $3.1 \pm 0.2$ & $3.5 \pm 0.3^{*}$ & $3.2 \pm 0.0^{*}$ & $3.0 \pm 0.2$ & $3.7 \pm 0.5$ & $3.3 \pm 0.5$ & $3.6 \pm 0.3$ \\
\hline
\end{tabular}


Table V. Flap Number and Flap to Capsule Fraction Difference for Carrier-Based Budesonide Formulations and Carrier-Free Rifampicin Formulations Characterized from ACGcaps ${ }^{\mathrm{TM}} \mathrm{HI}$, Embocaps ${ }^{\circledR}$ VG, Vcaps ${ }^{\circledR}$, and Quali-V® I Capsules at 2-kPa and 4-kPa Drop Conditions. Flap Number is Defined as the Number of Attached Flaps on the Capsule Pieces After NGI. Flap to Capsule Fraction is Defined as the Portion of Capsule Pieces with Attached Flaps Among All Actuated Capsule Pieces

\begin{tabular}{|c|c|c|c|c|c|c|c|c|c|}
\hline \multirow[t]{2}{*}{ Capsules types } & & \multicolumn{2}{|c|}{ Embocaps ${ }^{\circledR}$ VG } & \multicolumn{2}{|c|}{ Vcaps ${ }^{\circledR}$} & \multicolumn{2}{|c|}{ Quali-V® I } & \multicolumn{2}{|c|}{ ACGCAPS ${ }^{\mathrm{TM}} \mathrm{HI}$} \\
\hline & & $2 \mathrm{kPa}$ & $4 \mathrm{kPa}$ & $2 \mathrm{kPa}$ & $4 \mathrm{kPa}$ & $2 \mathrm{kPa}$ & $4 \mathrm{kPa}$ & $2 \mathrm{kPa}$ & $4 \mathrm{kPa}$ \\
\hline \multirow[t]{2}{*}{ Total flap number after NGI } & Carrier-based & 21 & 24 & 15 & 11 & 33 & 25 & 28 & 28 \\
\hline & Carrier-free & 6 & 3 & 2 & 2 & 7 & 3 & 5 & 3 \\
\hline \multirow[t]{2}{*}{ Flap to piercing fraction after NGI (\%) } & Carrier-based & 52.5 & 60 & 37.5 & 27.5 & 82.5 & 62.5 & 70 & 70 \\
\hline & Carrier-free & 75 & 37.5 & 25 & 25 & 87.5 & 37.5 & 62.5 & 37.5 \\
\hline
\end{tabular}

variability of this set of data appeared to have a potential relationship to the variability of $M M A D$. However, further studies need to be conducted to verify the existence of this relationship. However, when applying carrier-free formulation, Quali-V® I capsules appeared to exhibit a pressure drop dependency on the area, with the lower pressure drop condition resulting in the smallest open area and the higher pressure drop condition resulting in the highest open area among the capsules. Since the piercing needle is the same at each experiment, one explanation for this pressure droprelated trend can be the differences in the hardness of the capsule domes (where piercing is applied) from different capsule suppliers. The existed study has shown that a harder capsule dome increases puncture force, which is bad for aerosol performance (44). The same conclusion can be obtained from our study as well, in which Embocaps ${ }^{\circledR} \mathrm{VG}$ owned the smaller hardness of the capsule's domes.

Additionally, the 'flap' number differences among different capsules may result from the stiffness and hardness of the capsule domes. Many previous studies reported less force on both the puncturing of the shell and, in crushing the ends, produced more regular aperture in shape but less shedding of pieces $(34,45,46)$. From our study, Vcaps $®$ capsule, with high capsule dome hardness, had fewer flaps attached after device actuation and powder emission. Therefore, it may be reasonable to conclude that the capsule domes with high hardness could result in less flaps after piercing.

Lastly, result differences between these HPMC
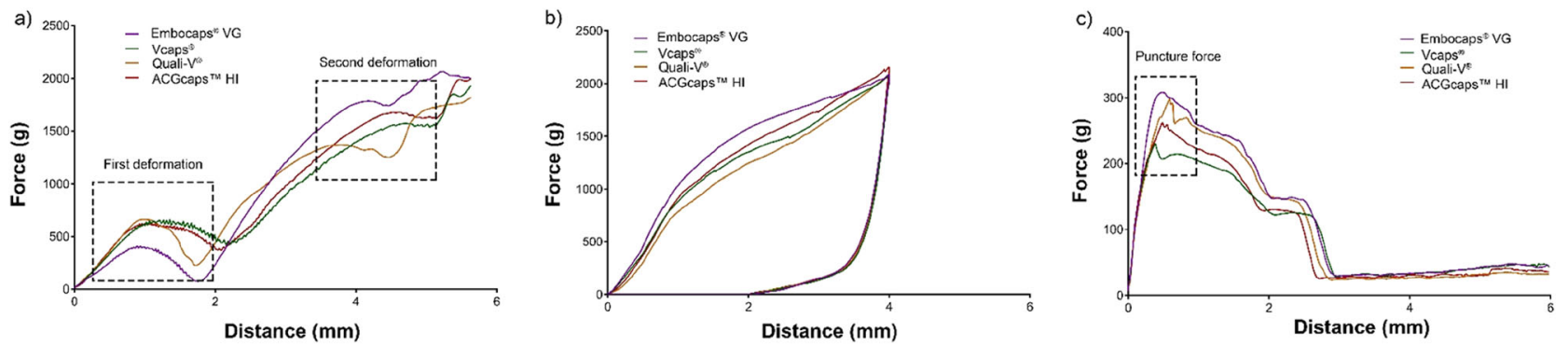

Fig. 7. a Graphical representation of the first and second deformations observed in Embocaps ${ }^{\circledR}$ VG, Vcaps ${ }^{\circledR}$, Quali-V® ${ }^{\circledR}$, and $A C G c a p s^{T M}$ HI DPI-grade capsules tested by vertical deformation methodology. b Graphical representation of the force changes observed in Embocaps ${ }^{\circledR}$ VG, Vcaps ${ }^{\circledR}$, Quali-V® I, and ACGcaps ${ }^{\mathrm{TM}}$ HI DPI-grade capsules measured by horizontal press methodology. $\mathbf{c}$ Graphical representation of the average puncture strength observed in Embocaps ${ }^{\circledR}$ VG, Vcaps ${ }^{\circledR}$, Quali-V® I, and ACGcaps ${ }^{\mathrm{TM}}$ HI DPI-grade capsules in vertical puncture test

Table VI. Descriptive Statistics for the Texture Properties of Quali-V®, ACGcaps ${ }^{\mathrm{TM}}$ HI, Embocaps ${ }^{\circledR}$ VG, and Vcaps ${ }^{\circledR}$ DPI-Grade Capsules $\left({ }^{\mathbf{\Delta}} P<0.05,{ }^{\mathbf{\Delta}} P<0.01\right.$; All Compared with the Embocaps ${ }^{\circledR}$ VG Group; ${ }^{\star} P<0.05,{ }^{\star *} P<0.01$; All Compared with the Quali-V ${ }^{\circledR}$ I Group; $* P<0.05, * * P<0.01$, All Compared with the Vcaps ${ }^{\circledR}$ Group)

\begin{tabular}{|c|c|c|c|c|}
\hline \multirow[t]{2}{*}{ Capsule type } & \multicolumn{2}{|l|}{ Deformation (vertical) } & \multirow[t]{2}{*}{ Capsule Stiffness (horizontal) $(\mathrm{g} * \mathrm{~mm})$} & \multirow[t]{2}{*}{ Puncture strength (g) } \\
\hline & First deformation (g) & Second deformation (g) & & \\
\hline Embocaps $\AA_{\text {VG }}$ & $415.7 \pm 63.9$ & $1811.2 \pm 101.3^{\text {+** }}$ & $5677.5 \pm 360.4^{200}$ & $315.1 \pm 50.2 * *$ \\
\hline Vcaps ${ }^{\circledR}$ & $640.6 \pm 47.4^{\wedge}$ & $1617.9 \pm 140.7^{\mathbf{*} *}$ & $5102.8 \pm 134.1^{\mathbf{4 *}}$ & $232.5 \pm 18.3$ \\
\hline Quali-V® I & $670.5 \pm 96.4^{\boldsymbol{\Lambda}}$ & $1405.8 \pm 69.2$ & $4805.1 \pm 189.5$ & $319.1 \pm 25.3 * *$ \\
\hline ACGcaps $^{\mathrm{TM}}$ HI & $627.6 \pm 41.6^{\wedge}$ & $1681.4 \pm 81.7^{\circ}$ & $5325.6 \pm 241.2^{*}$ & $272.5 \pm 25.9 *$ \\
\hline
\end{tabular}


inhalation-grade capsules may due to the capsule composition (e.g., different types of HPMC), processing, and manufacturing detail differences (not publicly available). Consideration of the relationship between capsule properties and processing history in future studies could provide additional insights.

\section{CONCLUSION}

In conclusion, we discovered in this study that selection of inhalation-grade capsules can be a crucial component in the creation of future innovative inhalation therapies. Depending on the DPI formulation and the intended performance goals, the best capsule type will be determined. The capsule type influenced $E F, R F, F P F$, and $M M A D$ in the carrier-free formulation (e.g., rifampicin in this study). Even though no statistically significant changes in performance were discovered for the carrier-based formulation, aerosol performance variability as well as pierced-flap detachment may influence capsule type selection. Overall, for the specific budesonide carrier-based formulation tested in this study, Embocaps ${ }^{\circledR}$ VG capsule displayed lowest variability, and for the rifampicin carrier-free formulation, this capsule type also showed improved aerosol performance. In developing new inhaled capsule-based formulations, product development should evaluate different capsule system to find optimal performance.

\section{AUTHOR CONTRIBUTION}

LD, ADB, and HDCS contribute to the conceptualization and design of the work. LD, ADB, RT, CL, and Q (J) Z performed all of the experiments and data acquisition. Data was analyzed and visualized by LD, ADB, and RT. LD wrote the original draft, while HDCS, JK, and MM helped with review and editing. All authors have read and agreed to the published version of the manuscript.

\section{FUNDING}

The ACG North America/ACG Scitech Centre financially supported this study.

\section{DECLARATIONS}

Conflict of Interest Hugh D. C. Smyth, one of the paper's authors, works on inhaled product development for Respira Therapeutics, Via Therapeutics, Nob Hill Therapeutics, and Cloxero Therapeutics. The University of Texas at Austin has reviewed and approved the conditions of the agreement in accordance with its research objectivity policy. Ashlee Brunaugh owns stocks in both CloXero Therapeutics and Via Therapeutics companies. The University of Texas at Austin has reviewed and approved the conditions of the agreement in accordance with its research objectivity policy.

\section{REFERENCES}

1. Ding L, Brunaugh AD, Stegemann S, Jermain SV, Herpin MJ, Kalafat $\mathrm{J}$, et al. A quality by design framework for capsulebased dry powder inhalers. Pharmaceutics. 2021;13(8):1213.
2. Lawrence XY, Li BV. FDA bioequivalence standards: Springer; 2014.

3. Weers JG, Miller DP. Formulation design of dry powders for inhalation. J Pharm Sci. 2015;104(10):3259-88.

4. Brunaugh AD, Ding L, Wu T, Schneider M, Khalaf R, Smyth HDC. Identification of stability constraints in the particle engineering of an inhaled monoclonal antibody dried powder. J Pharm Sci. 2021. https://doi.org/10.1016/j.xphs.2021.08.022.

5. Donovan MJ, Kim SH, Raman V, Smyth HD. Dry powder inhaler device influence on carrier particle performance. J Pharm Sci. 2012;101(3):1097-107.

6. Zhou QT, Tong Z, Tang P, Citterio M, Yang R, Chan H-K. Effect of device design on the aerosolization of a carrier-based dry powder inhaler - a case study on Aerolizer ${ }^{\circledR}$ Foradile ${ }^{\circledR}$. AAPS J. 2013;15(2):511-22.

7. Coates MS, Chan H-K, Fletcher DF, Raper JA. Influence of air flow on the performance of a dry powder inhaler using computational and experimental analyses. Pharm Res. 2005;22(9):1445-53.

8. Ding L, Wang J, Cai S, Smyth H, Cui Z. Pulmonary biofilmbased chronic infections and inhaled treatment strategies. International Journal of Pharmaceutics. 2021;604:120768.

9. Brunaugh AD, Seo H, Warnken Z, Ding L, Seo SH, Smyth HD. Development and evaluation of inhalable composite niclosamide-lysozyme particles: a broad-spectrum, patientadaptable treatment for coronavirus infections and sequalae. PloS one. 2021;16(2):e0246803.

10. Jarvis S, Ind PW, Shiner RJ. Inhaled therapy in elderly COPD patients; time for re-evaluation? : Oxford University Press; 2007.

11. Van der Palen J, Klein J, Van Herwaarden C, Zielhuis G, Seydel E. Multiple inhalers confuse asthma patients. Eur Respir J. 1999;14(5):1034-7.

12. Anderson PJ. History of aerosol therapy: liquid nebulization to MDIs to DPIs. Respir Care. 2005;50(9):1139-50.

13. Berkenfeld K, Lamprecht A, McConville JT. Devices for dry powder drug delivery to the lung. AAPS PharmSciTech. 2015;16(3):479-90.

14. Wauthoz N, Hennia I, Dejaeger B, Ecenarro S, Amighi K. Proposed algorithm for healthcare professionals based on product characteristics and in vitro performances in different use conditions using formoterol-based marketed products for inhalation. Int J Pharm. 2017;530(1-2):415-29.

15. Edwards D. Applications of capsule dosing techniques for use in dry powder inhalers. Ther Deliv. 2010;1(1):195-201.

16. Jones BE. Manufacture and properties of two-piece hard capsules. Pharmaceutical Capsules: Pharmaceutical Press, London; 2004. p. 79-100.

17. Saim S, Horhota ST. Process for overcoming drug retention in hard gelatin inhalation capsules. Drug Dev Ind Pharm. 2002;28(6):641-54.

18. Renswouw DCv, Laarhoven ACv, Haren MJv, Bouvy ML, Weda M. Storage instructions for inhalation capsules: consequences of incorrect storage and adherence in daily practice. Journal of pharmacy practice. 2010;23(6):548-52.

19. Saleem I, Diez F, Jones B, Kayali N, Polo L. Investigation on the aerosol performance of dry powder inhalation hypromellose capsules with different lubricant levels. Int J Pharm. 2015;492(12):258-63.

20. Plourde R, Bovet J-M, Boyce CM, Ewing K, Richardson M. Performance of hypromellose (V-caps $\left.{ }^{\circledR}\right)$ capsules for unit dose dry powder inhalation devices. RDD Europe. 2009:289-92.

21. Ayala G, Díez F, Gassó MT, Jones BE, Martín-Portugués R, Ramiro-Aparicio J. Statistical tools and control of internal lubricant content of inhalation grade HPMC capsules during manufacture. Int J Pharm. 2016;503(1-2):36-40.

22. Wauthoz N, Hennia I, Ecenarro S, Amighi K. Influence of flow rate and uasage in drastic condition on the aerodynamic performance of a formoterol dry powder formulation using different kinds of capsules for inhalation. 2016.

23. Wauthoz N, Hennia I, Deleers M, Diez F, Amighi K, editors. Evaluation of the aerodynamic performance of formoterol dry powder using different capsules for inhalation: hypromellose versus gelatin from Qualicaps and Capsugel. Abstracts from The Aerosol Society Drug Delivery To the Lung 26; 2016: Journal of Aerosol Medicine and Pulmonary Drug Delivery. 
24. Faulhammer E, Wahl V, Zellnitz S, Khinast JG, Paudel A. Carrier-based dry powder inhalation: impact of carrier modification on capsule filling processability and in vitro aerodynamic performance. Int J Pharm. 2015;491(1-2):231-42.

25. Lavorini F, Pistolesi M, Usmani OS. Recent advances in capsule-based dry powder inhaler technology. Multidisciplinary respiratory medicine. 2017;12(1):11.

26. Newman SP. A comparison of lung deposition patterns between different asthma inhalers. Journal of Aerosol Medicine. 1995;8(s3):S-21-S-7.

27. Yazdi AK, Smyth HD. Implementation of design of experiments approach for the micronization of a drug with a high brittleductile transition particle diameter. Drug Dev Ind Pharm. 2017;43(3):364-71

28. Farkas DR. Development of high efficiency dry powder inhalers for use with spray dried formulations: Virginia Commonwealth University; 2017.

29. Marple VA, Olson BA, Santhanakrishnan K, Mitchell JP, Murray SC, Hudson-Curtis BL. Next generation pharmaceutical impactor (a new impactor for pharmaceutical inhaler testing). Part II: Archival calibration. Journal of Aerosol medicine. 2003;16(3):301-24.

30. O'Shaughnessy PT, Raabe OG. A comparison of cascade impactor data reduction methods. Aerosol Sci Technol. 2003;37(2):187-200.

31. Zhang Y, Yang N, Zhang Y, Hou J, Han H, Jin Z, et al. Effects of k-carrageenan on pullulan's rheological and texture properties as well as pullulan hard capsule performances. Carbohydrate Polymers. 2020:116190.

32. Mei X, Etzler FM, Wang Z. Use of texture analysis to study hydrophilic solvent effects on the mechanical properties of hard gelatin capsules. Int J Pharm. 2006;324(2):128-35.

33. Nakate $\mathrm{T}$, Yoshida $\mathrm{H}$, Ohike A, Tokunaga $\mathrm{Y}$, Ibuki $\mathrm{R}$, Kawashima Y. Formulation development of inhalation powders for FK888 using the E-haler ${ }^{\circledR}$ to improve the inhalation performance at a high dose, and its absorption in healthy volunteers. Eur J Pharm Biopharm. 2005;59(1):25-33.

34. Torrisi BM, Birchall JC, Jones BE, Díez F, Coulman SA. The development of a sensitive methodology to characterise hard shell capsule puncture by dry powder inhaler pins. Int J Pharm. 2013;456(2):545-52.

35. Chew NY, Chan H-K, Bagster DF, Mukhraiya J. Characterization of pharmaceutical powder inhalers: estimation of energy input for powder dispersion and effect of capsule device configuration. J Aerosol Sci. 2002;33(7):999-1008.

36. Chang RK, Raghavan KS, Hussain MA. A study on gelatin capsule brittleness: moisture transfer between the capsule shell and its content. J Pharm Sci. 1998;87(5):556-8.

37. Zhang J, Shu S, Song C, Zhou J, Hu Y. The relationship between stiffness variation and performance of electromagneticair spring vibration isolator. Adv Mech Eng. 2016;8(9):1687814016670293.

38. Faulhammer E, Kovalcik A, Wahl V, Markl D, Stelzer F, Lawrence $\mathrm{S}$, et al.Multi-methodological investigation of the variability of the microstructure of HPMC hard capsules. Int J Pharm. 2016;511(2):840-54.

39. Hickey AJ. Controlled delivery of inhaled therapeutic agents. J Control Release. 2014;190:182-8.

40. Wachtel H. Respiratory drug delivery. Microsystems for Pharmatechnology: Springer; 2016. p. 257-74.

41. Kondo T, Tanigaki T, Yokoyama H, Hibino M, Tajiri S, Akazawa $\mathrm{K}$, et al. Impact of holding position during inhalation on drug release from a reservoir-, blister-and capsule-type dry powder inhaler. J Asthma. 2017;54(8):792-7.

42. Jiang L, Tang Y, Zhang H, Lu X, Chen X, Zhu J. Importance of powder residence time for the aerosol delivery performance of a commercial dry powder inhaler Aerolizer ${ }^{\circledR}$. J Aerosol Med Pulm Drug Deliv. 2012;25(5):265-79.

43. Telko MJ, Kujanpää J, Hickey AJ. Investigation of triboelectric charging in dry powder inhalers using electrical low pressure impactor (ELPI ${ }^{\mathrm{TM}}$ ). Int J Pharm. 2007;336(2):352-60.

44. Kuentz M, Rothenhäusler B, Röthlisberger D. Time domain $1 \mathrm{H}$ NMR as a new method to monitor softening of gelatin and HPMC capsule shells. Drug Dev Ind Pharm. 2006;32(10):116573.

45. Sakuma S, Tochio S, Nagata S. Comparative investigation of hard capsules for inhalation. AAPS J. 2004;6(4).

46. Jones B. Quali-V®-I: a new key for dry powder inhalers. Drug Deliv Technol. 2003;3(6):2-7.

Publisher's Note Springer Nature remains neutral with regard to jurisdictional claims in published maps and institutional affiliations. 